\title{
Development and testing of innovative patient resources for the management of coronary heart disease (CHD): a descriptive study Julie Redfern*1, Elizabeth Ellis ${ }^{1}$, Tom Briffa ${ }^{2}$ and Saul B Freedman ${ }^{3}$
}

\author{
Address: ${ }^{1}$ School of Physiotherapy, University of Sydney, Sydney, Australia, ${ }^{2}$ School of Physiotherapy, Curtin University of Technology, Perth, \\ Australia and ${ }^{3}$ Department of Cardiology, Concord Hospital, Sydney, Australia \\ Email: Julie Redfern* - julieredfern@dodo.com.au; Elizabeth Ellis - elizabethellis@ozemail.com.au; Tom Briffa - T.Briffa@curtin.edu.au; \\ Saul B Freedman - ben@gmp.usyd.edu.au \\ * Corresponding author
}

Published: 06 August 2006

BMC Health Services Research 2006, 6:95 doi:10.1 186/1472-6963-6-95
Received: 29 March 2006

Accepted: 06 August 2006

This article is available from: http://www.biomedcentral.com//472-6963/6/95

(c) 2006 Redfern et al; licensee BioMed Central Ltd.

This is an Open Access article distributed under the terms of the Creative Commons Attribution License (http://creativecommons.org/licenses/by/2.0), which permits unrestricted use, distribution, and reproduction in any medium, provided the original work is properly cited.

\begin{abstract}
Background: Although heart disease is a major cause of morbidity and mortality the majority of patients do not access existing rehabilitation programs and patient resources are not designed to facilitate patient choice and decision-making. The objective of this study was to develop and test a series of risk factor modules and corresponding patient information leaflets for secondary prevention of CHD.
\end{abstract}

Methods: In phase one, a series of risk factor modules and management options were developed following analysis of literature and interviews with health professionals. In phase two, module information leaflets were developed using published guidelines and interviews of people with CHD. In phase three, the leaflets were tested for quality (DISCERN), readability (Flesch) and suitability (SAM) and were compared to the existing cardiac rehabilitation (CR) information leaflet. Finally, the patients assessed the leaflets for content and relevance.

Results: Four key risk factors identified were cholesterol, blood pressure, smoking and physical inactivity. Choice management options were selected for each risk factor and included medical consultation, intensive health professional led program, home program and self direction. Patient information needs were then identified and leaflets were developed. DISCERN quality scores were high for cholesterol (62/80), blood pressure (59/80), smoking (62/80) and physical activity (62/80), all scoring $4 / 5$ for overall rating. The mean Flesch readability score was 75 , representing "fairly easy to read", all leaflets scored in the superior category for suitability and were reported to be easy to understand, useful and motivating by persons with CHD risk factors. The developed leaflets scored higher on each assessment than the existing CR leaflets.

Conclusion: Using a progressive three phase approach, a series of risk factor modules and information leaflets were successfully developed and tested. The leaflets will contribute to shareddecision making and empowerment for persons with CHD.

\section{Background}

Coronary heart disease (CHD) is a chronic illness that is best managed when positive health behaviors become integrated into long-term lifestyle habits [1]. Secondary prevention of CHD involves risk factor reduction through control of health behaviors such as diet, physical activity, 
smoking and medication adherence using a coordinated approach and referrals to health professionals [2,3]. Modification of risk factors such as blood cholesterol, blood pressure (BP), physical inactivity, smoking, overweight, diabetes and depression can reduce cardiovascular events, the need for coronary revascularisation and improve quality of life (QOL) [4]. However, strategies are needed to motivate patients to consistently follow multidimensional treatment regimens [1].

Although attendance at cardiac rehabilitation (CR) programs is widely recommended $[5,6]$ there is significant under-use of facility-based programs in Australia [7,8] and internationally [9-11]. Despite clear short-term benefits for attendees, large groups of patients are not accessing, which presents an opportunity and challenge to improve CHD care [10]. Although many authors have suggested the need for development of alternative models, these have not yet been widely described or implemented. One pilot study investigated secondary prevention of CHD using a 'modular' approach [12]. For the study, a metropolitan cardiac rehabilitation program was offered as individual components, or modules, based on patient need rather than an all-or-nothing exercise-based approach. Although only 26 subjects participated, the study demonstrated enhanced completion rates and cost effectiveness. The pilot study was an important step from standard cardiac rehabilitation however, modules were still conducted in a group environment and were based on education without formal goal setting and follow-up and no patient information leaflets were provided. Results of the pilot study suggest that development and evaluation of more detailed unique risk factor modules may enhance long-term outcomes.

The development of patient resources based on multidimensional behavior modification techniques may enhance compliance with long-term risk factor interventions [13]. Techniques include goal setting, choice and offering a wide range of individually-tailored services [6]. For chronic disease, change needs to be conceptualised in a positive light to reduce anxiety rather than focusing on negative aspects of making a change [1]. Setting of mutually-agreed and realistic goals with clear time-frames enhances active patient orientation and motivation which facilitates behavior change $[1,14]$. The inclusion of a confidence rating for goal achievement may improve the health professional's insight into a patient's motivation to change [1].

Offering choice, in situations where there are several management options, based on individual need and preference is a further method of enhancing active patient orientation [15]. It is also suggested that options offered as a menu of strategies are more successful because it encourages each patient's task to be one of "choosing rather than refuting" [1]. Providing choice allows different people to respond to health professionals in different ways based on each persons needs at different times. We have chosen the term 'guided self-choice' to describe this model which creates a collaborative encounter, which is similar to the spirit of behavior counseling [16].

Facilitation of collaborative relationships, shared decision-making and communication of expectations in a supportive environment helps motivate behavior change and contribute to the disease management process $[17,18]$. Formation of collaborative relationships decreases patient anxiety and dissatisfaction that is often related to uncertainty and lack of information, explanation and feedback [19]. Studies have demonstrated that encouraging patients to participate in treatment decisions improves health status, QOL $[20,21]$, satisfaction, compliance and treatment outcomes [22]. More specifically, patients with a higher degree of active orientation are more likely to comply with treatment recommendations for BP [18], diabetes and physical activity [23].

Although provision of effective education is an essential component of healthcare [24], patients tend to forget approximately half the information provided [25]. Providing supplementary written information increases patients' knowledge of disease [26-28] and reduces distress [29] and decisional conflict [30] because it reinforces verbal instructions and serves as a home resource [31]. Effective patient information must be evidence-based, clearly presented and most importantly, involve patients throughout the process of development [32-34]. Information materials should succinctly deal with the relevant messages [31] be written in active voice with personalised messages and use simple terminology [14,31,35]. Layout should be clear, simple and consistent [14,35] and use subheadings to allow patients to efficiently sift through the information $[17,31]$.

Various studies have tested patient education materials including those for drug information [36,37], prostate cancer [38], asthma [39], cardiac catheterization [40] and about general practice [41]. Two studies have highlighted the importance of devoting considerable effort to the development of educational materials and including patients throughout the entire process $[42,43]$. Both studies used a progressive approach and demonstrated that if a leaflet is written at an easily readable level and in collaboration with patients, knowledge is increased. The objectives of this study were to develop and evaluate a series of cardiac risk factor modules and corresponding information leaflets for secondary prevention of CHD. 


\section{Methods \\ Phase I - Development of secondary prevention risk factor modules}

The objective of phase one was to develop a series of CHD secondary prevention risk factor modules each containing a menu of management options. Major CHD risk factors were identified after a systematic search of electronic databases and cross-reference of publications for consistent risk factors that put the greatest proportion of patients at the highest risk. In addition, six health professionals including allied health, medical and nursing, were interviewed about risk factors and their prevention. They were specifically asked which risk factors were the most prevalent, which presented the greatest CHD risk.

Once key risk factors were identified, the authors conducted an investigation of the relevant and available management options within the area health service. Key areas included the availability of lipid clinics, smoking cessation programs and local exercise and walking groups. Searches were conducted via internet searches, telephone contacts with health professionals and in person. Contact details, general information and costs, if applicable, for each service were recorded.

\section{Phase 2 - Development of module information leaflets} The objective of phase two was to develop information leaflets for each of the modules, developed in phase 1, using published guidelines [10]. Semi-structured interviews of volunteers with at least one CHD risk factor were also conducted to identify their feedback for the leaflets along with ideas to enhance motivation for behavior change. Potential volunteers were identified consecutively from an outpatient clinic at a local hospital, were between 30-60 years and had least one of the relevant CHD risk factors.

Each interview was guided with a series of seven pre-developed questions which focused on the type and volume of information people would like about CHD risk factors and what information would be motivating. All participants were also asked if they wanted to be involved in the management decision-making and the interview was concluded with an open question asking for any further comments.

After systematically addressing each of the published guidelines [17] and using themes generated from interviews of health professionals and people with CHD risk factors, the module information leaflets were drafted. Apart from a heading and relevant logos, additional space was provided for documenting the risk factor level, goal, time frame for achievement and information about the nationally recommended level. The front page also included a series of options, each with a 'tick box', from which the patient could choose a single preferred management option. Each information leaflet also included general information about CHD, suggestions for reducing the risk factor and space for documenting phone numbers and appointment details. A point-form layout with size 12 font in an A5 size book format was chosen for ease of reading and visual appeal.

\section{Phase 3 - Testing of module information leaflets}

The objective of phase three was to evaluate the module information leaflets for quality, readability and suitability and content and relevance. The newly developed leaflets were also compared to the existing CR information leaflet that was obtained from the rehabilitation coordinator. Two independent researchers completed all assessment tools for each leaflet and the mean scores were calculated for each subsection.

Quality of the leaflets was evaluated using the DISCERN instrument [44] which is a 16 item questionnaire and is a reliable and valid measure [44-46] with three sections reliability of the publication, quality of the information about treatment choices and overall rating. Each item is scored on a 5-point Likert scale from one (low quality) to five (high quality). An aggregate score greater than 75 represents very high quality and a final score of less than 15 represents very low quality [44].

Readability of the leaflets was evaluated using the Flesch readability formula which assesses the average number of syllables per word and the average number of words per sentence [47]. The final score for reading ease are out of a possible 100, scores between 70 and 100 represent matter that is understandable by people who have completed the fourth grade of schooling [47]. The human interest score represents the amount of personalisation in the piece of writing, scores range from zero (no human interest) to 100 (extensive personal interest). The Flesch formula has been demonstrated to be reliable and highly correlated with other readability formulae for analysis of healthbased literature [48].

The leaflets were evaluated for suitability using the Suitability Assessment of Materials (SAM) instrument [49]. The SAM has 22-items that test six criteria of written materials - content, literacy demand, graphics, presentation, learning stimulation or motivation and cultural appropriateness. Final aggregate sores greater than $70 \%$ are judged to be superior, scores between $40 \%-69 \%$ are deemed adequate and scores below $40 \%$ are considered unsuitable. The SAM has been validated following evaluation of a nutritional leaflet by more than 150 health professionals [49]. 
To evaluate content, relevance and usefulness of the leaflets from a patient's perspective, a group of people with at least one CHD risk factor completed a questionnaire. The questionnaire was completed anonymously in the hospital outpatient clinic and was made up of nine Likert items across four sections - overall rating, heart disease information, treatment options and style and readability. The questionnaire was designed to obtain opinions on core attributes previously outlined [17] - content adequacy (understanding), relevance (a balanced view) and matching of information with the individual's experience (visual appeal). Readers were asked to rate each question on a five-point visual analogue scale, higher scores represented more positive responses. Space was also provided for comments and identification of words not understood.

A target recruitment rate of 10 participants per risk factor was set, providing a total of 40 participants across the four risk factors. Participants were recruited consecutively from a local hospital clinic and were included if they had at least one of the relevant CHD risk factor and if they volunteered to review the leaflet. The results for the newly developed and the existing CR leaflets were compared using t-tests for continuous variables and chi-squared for proportions, two-tailed p-values of $<0.05$ were considered significant.

\section{Ethical approval}

Ethical approval for the study was provided by the Central Sydney Area Health Service CRGH Zone and the University of Sydney. Written and informed consent was obtained from all participants prior to commencement.

\section{Results \\ Phase I - Development of secondary prevention risk factor modules}

Following literature analysis and interviews with health professionals, four key CHD risk factors were chosen for development into modules and corresponding information leaflets. The risk factors chosen were cholesterol management as well as BP-lowering, smoking cessation and physical inactivity which could be chosen based on need and preference. High cholesterol was chosen because it is a very highly prevalent and continuous risk factor where the higher the value, the higher the risk. In Australia, about half the adult population have high cholesterol [50]. Importantly, cholesterol-lowering decreases the relative risk for major coronary events by $27 \%$, for CHD mortality by $27 \%$ and for all cause mortality by $21 \%$ [51]. For these reasons along with the strong recommendation of the Cardiologist interviewed and based on the secondary prevention benefit of cholesterol-lowering, it was decided that cholesterol lowering would be a priority risk factor module that all patients should be encouraged to participate in.

High BP was chosen because of its prevalence and the graded relationship between $\mathrm{BP}$ and risk of CHD risk [52]. Approximately $28 \%$ of the Australian adult population have high BP [50]. BP lowering has been found to cause a $12 \%$ reduction in cardiovascular events and a $22 \%$ reduction in mortality [53]. Smoking was a chosen key risk factor because it accounts for approximately $13 \%$ of Australian deaths annually [54]. In addition, smoking cessation has both dose dependent and reversible improvements on endothelial function [55]. Physical activity was also chosen because $44 \%$ of the Australian adult population do not participate in a level of physical activity that is sufficient to achieve a health benefit [54]. In addition, increasing physical activity levels can have a positive effect on other risk factors such as cholesterol, BP, overweight, diabetes and depressed mood [56].

Four common management options were identified were - medical consultation, a health professional-led intervention, a home program and self help (Table 2). Where practical, each management option was incorporated into each module to provide a menu-style choice. For the medical consultation, patients were to be encouraged to initiate contact with their doctor, to record and follow their advice. For health professional-led intervention, the risk factor was managed by participation in a supervised, structured program that may be hospital or community based. For the home program option, patients were to manage the risk factor through participation in a homebased program. Finally, in the self-help option, patients could choose to manage the risk factor through their own means and were provided with sources of local information including the internet, telephone numbers and books. At the completion of phase 1, although all patients were to be encouraged to participate in cholesterol-lowering, each module followed a guided self-choice approach where patients could choose, in collaboration with a health professional, the management option to suit their individual needs or preference.

\section{Phase 2 - Development of module information leaflets}

Common themes identified from published guidelines [17] were that the leaflets should be simple and positive in design and language, repeat key terms, clearly identify treatment options and importantly that patients should be involved throughout development and testing. A group of 12 people with at least one CHD risk factor volunteered to be interviewed, nine were male, age ranged from 30-52 years with a mean of 47 years. Seven participants had experienced previous angina, one had a previous myocardial infarction and three had no previous acute coronary syndrome (ACS). Common content-related themes 
included widespread request to have basic information that provided reassurance as well as realistic and practical methods for managing the risk factor (Table 1). Participants suggested the use of a positive and motivating tone, most felt strongly about the provision of contact details and the need for space to write questions and all commented on the need for simplicity and brevity.

Of the participants with high cholesterol, $100 \%$ wanted to know their own and the recommended level and 66\% wanted information about cholesterol testing and medications. Of the participants with high BP, 100\% requested information about the effects of $\mathrm{BP}$ on the heart and about medications for BP. Of the patients who were physically inactive, $100 \%$ expressed a need for simple and practical information about safe activities. Of the current smokers interviewed, $100 \%$ said they wanted information about how to quit and none wanted information about why. For all risk factors, $100 \%$ of participants felt strongly about the need for shared decision-making and tailoring management to suit their lifestyle.

\section{Phase 3 - Testing of module information leaflets (Table 3 and Table 4)}

The final calculated results relating to leaflet quality, out of a possible 80, for the DISCERN were 61.5 for blood cholesterol, 59 for blood pressure, 62 for smoking and 61.5 for physical activity. All leaflets scored $4 / 5$ for overall rating and the mean results for each of the three key DISCERN sections was calculated (Table 3 ). Flesch readability scores for the four leaflets ranged from 68 to 82 with a mean of 75 . The overall score for the combined module leaflets was 75, placing them in the "fairly easy to read" category [47]. When tested for suitability, all four module information leaflets scored greater than an $80 \%$ SAM rating placing them all in the superior category. Compared to the existing CR information leaflet, the newly developed module leaflets scored significantly higher on the DISCERN $(\mathrm{p}=0.04)$, Flesch $(\mathrm{p}=0.01)$ and SAM $(\mathrm{p}<0.001)$ assessment tools.

A total of 40 participants, 10 for each module, tested the leaflets for content and relevance. Demographic data and the questionnaire results for each module were summarised, scores were all out of a possible five (Table 4). General suggestions given by participants relating to presentation and understanding included increasing the space between the goal and management options, providing more space to write notes and placing the goal and measured risk factor in a shaded box to enhance clarity. Specific comments - "motivates me to lower my cholesterol", "sufficient information", "easy to understand", "clear language", "options are clear and in a logical order" and "providing a variety of options is more motivating than someone just telling me what to do". One participant believed the term "cessation" on the smoking leaflet

Table I: Identified information needs of patients with heart disease

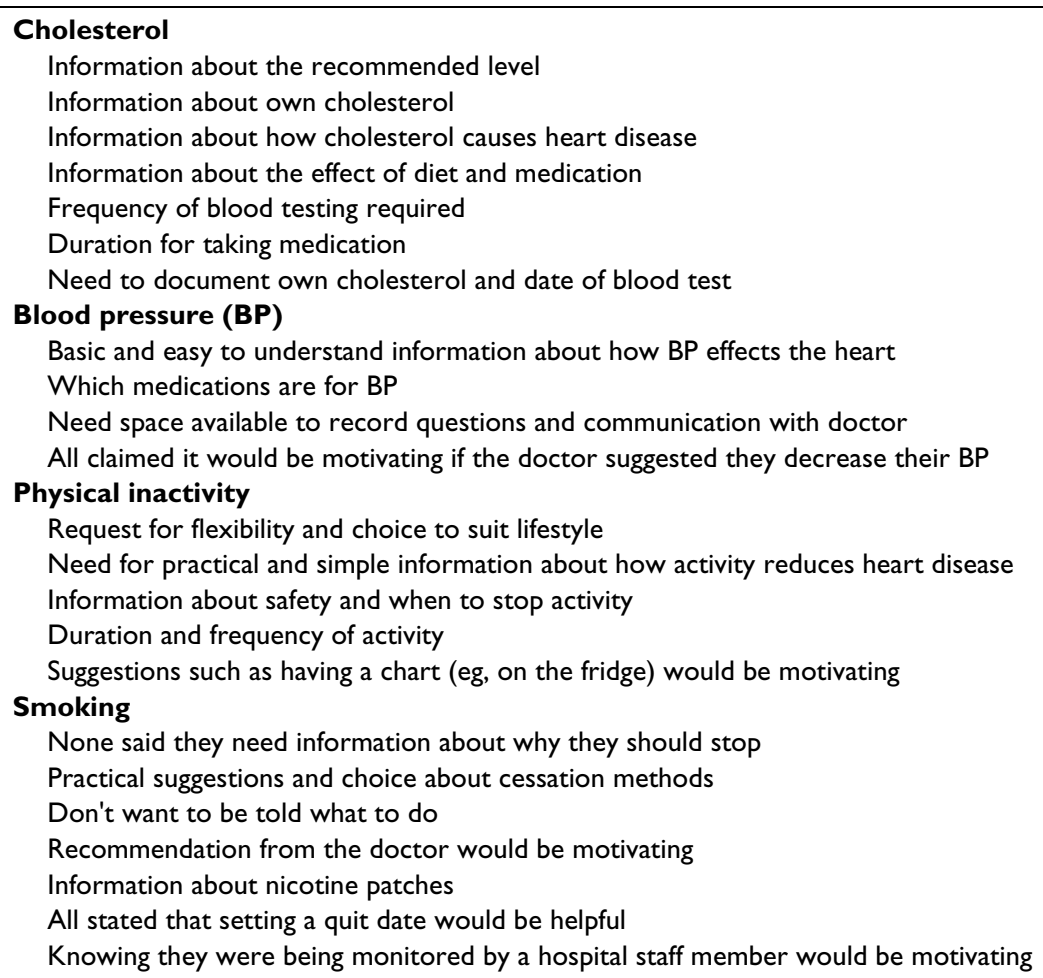


Table 2: Management options for BP, smoking cessation and physical activity

\begin{tabular}{|c|c|c|c|}
\hline Choice Options & BP Management & Smoking Cessation & Physical Activity \\
\hline Medical consultation & $>_{\text {Follow doctors advice }}$ & $>_{\text {Follow doctors advice }}$ & $D_{\text {Follow doctors advice }}$ \\
\hline $\begin{array}{l}\text { Health professional-led } \\
\text { intervention }\end{array}$ & $>_{\text {Group session at local hospital }}$ & $\begin{array}{l}D_{\text {Local hospital dedicated }} \\
\text { program for smoking cessation }\end{array}$ & $\begin{array}{l}\text { Six week supervised group } \\
\text { exercise }\end{array}$ \\
\hline intervention & $>$ Outpatient diet review & & $\begin{array}{l}>\text { Community group walking } \\
\text { program }\end{array}$ \\
\hline Home program & $\begin{array}{l}\text { Home medication, exercise } \\
\text { program prescribed by doctor and } \\
\text { allied health professional }\end{array}$ & $>$ Nil relevant & $\begin{array}{l}\text { Written Home exercise } \\
\text { program prescribed by allied } \\
\text { health professional }\end{array}$ \\
\hline \multirow[t]{3}{*}{ Self-directed } & $>_{\text {Heartline }}$ & $>_{\text {Quitline }}$ & $\begin{array}{l}D_{\text {Physical activity resources }} \\
\text { accessed at own discretion }\end{array}$ \\
\hline & $>_{\text {Private dietitian }}$ & $>_{\text {Heartline }}$ & \\
\hline & $>_{\text {Reading, multi-media resources }}$ & & \\
\hline
\end{tabular}

should be changed to "quitting". All changes suggested by the volunteers were incorporated into the leaflets.

\section{Discussion}

This study describes the development and testing of a new series of CHD risk factor modules and corresponding information leaflets for patients. From the literature and input from consumers and health professionals, it was determined that cholesterol-lowering would be a mandatory module and remaining risk factors (BP management, physical inactivity and smoking cessation) would be optional modules. A menu of management options was developed and adapted for each of the risk factors to facilitate active choice rather than encourage refuting and scru-

Table 3: Module and existing information leaflet scores for quality, readability and suitability

\begin{tabular}{|c|c|c|c|c|c|c|c|c|}
\hline & & $\begin{array}{c}\text { Blood } \\
\text { cholesterol } \\
(\text { mean } \pm S D)\end{array}$ & $\begin{array}{l}\text { Blood pressure } \\
\quad(\text { mean } \pm \text { SD) }\end{array}$ & $\begin{array}{l}\text { Tobacco } \\
\text { smoking (mean } \\
\pm \text { SD) }\end{array}$ & $\begin{array}{l}\text { Physical activity } \\
\text { (mean } \pm \text { SD) }\end{array}$ & $\begin{array}{l}\text { Combined new } \\
\text { leaflets (mean } \\
\pm S D)\end{array}$ & $\begin{array}{l}\text { Existing CR } \\
\text { leaflets (mean } \\
\quad \pm S D \text { ) }\end{array}$ & $p$ \\
\hline \multirow{4}{*}{$\begin{array}{c}\text { Quality } \\
\text { (DISCERN } \\
\text { instrument) }\end{array}$} & Reliability $\dagger$ & $3.7 \pm 1.4$ & $3.5 \pm 1.3$ & $3.5 \pm 1.4$ & $3.8 \pm 1.2$ & $3.6 \pm 1.3$ & $2.9 \pm 1.9$ & 0.002 \\
\hline & Choicest & $3.9 \pm 1.2$ & $3.8 \pm 1.2$ & $4.2 \pm 0.9$ & $3.9 \pm 1.2$ & $3.9 \pm 1.2$ & $2.6 \pm 2.0$ & 0.000 \\
\hline & $\begin{array}{l}\text { Overall } \\
\text { ratingt }\end{array}$ & $4.0 \pm 0.0$ & $4.0 \pm 0.0$ & $4.0 \pm 0.0$ & $4.0 \pm 0.0$ & $4.0 \pm 0.0$ & $2.0 \pm 0.0$ & 0.000 \\
\hline & Final result $\S$ & 61.5 & 59.0 & 62.0 & 61.5 & 60.5 & 43.0 & - \\
\hline \multirow{5}{*}{$\begin{array}{l}\text { Readability } \\
\text { (Flesch) }\end{array}$} & Reading ease $\ddagger$ & 68 & 75 & 82 & 77 & 78 & 32 & 0.015 \\
\hline & Description & standard & fairly easy & easy & fairly easy & fairly easy & difficult & - \\
\hline & $\begin{array}{c}\text { Human } \\
\text { interest } *\end{array}$ & 71 & 70 & 70 & 70 & 70 & 4 & 0.000 \\
\hline & Description & dramatic & dramatic & dramatic & dramatic & dramatic & scientific & - \\
\hline & $\begin{array}{l}\text { Population } \\
\text { able to } \\
\text { understand }\end{array}$ & $75 \%$ & $80 \%$ & $86 \%$ & $80 \%$ & $79 \%$ & $24 \%$ & 0.000 \\
\hline $\begin{array}{c}\text { Suitability } \\
\text { (SAM) rating } \\
* *\end{array}$ & & $83 \%$ & $81 \%$ & $81 \%$ & $81 \%$ & $81 \%$ & $23 \%$ & 0.000 \\
\hline
\end{tabular}

SAM = suitability assessment of materials, $C R=$ cardiac rehabilitation.

$\dagger$ scored on a 5-point Likert scale from I (low quality) to 5 (high quality).

$\S$ scores out of a possible 80 where higher scores represent higher quality.

$\ddagger$ scores out of a possible 100, higher scores represent greater ease of understanding.

* scores out of a possible 100, higher scores represent higher personal interest.

** sores out of a possible 100, higher scores represent greater suitability.

$p=$ probability of test statistic for difference between the combined new leaflets and the existing CR leaflets 
Table 4: Rating of content and relevance of module information leaflets by patients

\begin{tabular}{cccccc}
\hline & $\begin{array}{c}\text { Blood Cholesterol } \\
(\text { mean } \pm \text { SD) }\end{array}$ & $\begin{array}{c}\text { Blood Pressure (mean } \\
\pm \text { SD) }\end{array}$ & $\begin{array}{c}\text { Tobacco Smoking } \\
(\text { mean } \pm \text { SD) }\end{array}$ & $\begin{array}{c}\text { Physical Activity } \\
(\text { mean } \pm \text { SD) }\end{array}$ & $\begin{array}{c}\text { Combined results } \\
(\text { mean } \pm \text { SD) }\end{array}$ \\
\hline $\begin{array}{c}\text { Age (years) } \\
\% \text { male }\end{array}$ & $62 \pm 21$ & $55 \pm 22$ & $59 \pm 21$ & $57 \pm 19$ & $58 \pm 21$ \\
& 40 & 40 & 50 & 45 & $4.2 \pm 0.6$ \\
\hline Overall rating $\dagger$ & $4.2 \pm 0.9$ & $4.3 \pm 0.7$ & $4.3 \pm 0.7$ & $4.4 \pm 0.5$ & $4.3 \pm 0.7$ \\
Heart disease $\dagger$ & $3.6 \pm 0.7$ & $4.4 \pm 0.7$ & $4.5 \pm 0.5$ & $4.7 \pm 0.7$ \\
$\begin{array}{c}\text { Treatment options } \dagger \\
\text { Style and readability } \dagger\end{array}$ & $4.5 \pm 0.6$ & $4.7 \pm 0.4$ & $4.7 \pm 0.4$ & $4.4 \pm 0.5$ & $4.4 \pm 0.5$ \\
\hline
\end{tabular}

tscored on a 5 -point Likert scale from I (low quality) to 5 (high quality)

tinising that often occurs if options are presented one by one [1].

Development of the risk factor modules was achieved by interview with health professionals and a systematic review of management options available in the local area. After identifying four consistent management options, each was then tailored for the four chosen risk factors. The management options included choices where the patient could take a more passive role and choices where the patient could take a more independent and active role in their health-care (self-help). Therefore, the choices within each module were designed to facilitate a successful outcome, or risk factor reduction, for a diverse range of personality types and for patients at different stages since their original heart event.

The information needs expressed by patients in phase two compared favourably with the suggestions given in published guidelines [17], for example, the need for specific and honest information, a concise design and the availability of treatment options. We addressed both process and content guidelines by involving patients and health professionals, reviewing clinical evidence and evaluating the leaflets. Therefore, this study provides an extension from published guidelines, documents the specific information needs of patients with CHD risk factors and highlights the importance of identifying patient needs using interview, as suggested by previous researchers [48].

When tested for quality, all four newly developed module information leaflets scored ratings greater than 'moderate' level on the DISCERN instrument. The leaflets were designed to provide basic information about the risk factor rather than comprehensive information about heart disease. All leaflets scored highly on items relating to treatment options, sources of additional information and support for shared decision-making. This finding confirms the pre-defined intention of the developed resources, particularly in terms of shared decision making.
When assessed for readability, the majority of leaflets scored in the 'fairly easy to read' Flesch category. The mean Flesch reading ease score for the leaflets was 75 , indicating that $80 \%$ of the general population would be expected to understand it [35]. Many of the polysyllabic words (eg, blood cholesterol) appeared repetitively in the leaflets and hence the Flesch score probably underestimated reading ease. Importantly, studies comparing readability and knowledge, found that a leaflets reading ease was associated with a significant increase in knowledge $[36,41]$.

The blood cholesterol leaflet scored the lowest readability, probably because the word 'cholesterol' was repeated nine times in the 100 word sample assessed. The word 'cholesterol' represents a four syllable word which would have adversely affected the Flesch score. Previous authors have criticised the use of readability formulas because they disregard patients' familiarity with certain words [39]. Importantly, when interviewed, no participants with high cholesterol identified the 'cholesterol' as a term they did not understand. A similar scenario existed for the physical activity leaflet. While the readability score is a useful objective method of assessing written education material, the scores do not consider patient motivation, visual attractiveness and conceptual background of the reader. Therefore, the score, as suggested by previous authors [49], was only used as one element for consideration when developing the written material.

When assessed for suitability, all leaflets scored in the category representing 'superior' suitability [57]. Each leaflet scored similarly because each followed the same basic style and layout and the SAM is weighted fairly heavily in terms of these aspects. The main deficiency in each of the information leaflets was the reading level score. To achieve the maximum score the reading level had to be of grade 5 or less. As described previously it is likely that the module information leaflets scored greater reading age then grade five due to the repetitive use of polysyllabic words such as "cholesterol" and "physical activity". 
Compared to the newly developed module leaflets, the existing CR information leaflets scored poorly on all assessment tools. The CR leaflets were not dated, did not provide sources of additional information, presented an unbalanced view where only treatment was offered and they did not support shared decision making. Also, the CR leaflets were written in complex language and passive voice within minimal personalisation. These findings highlight the importance of involving patients throughout the process of development and demonstrate the superiority of the newly developed module information leaflets.

High scores for content and relevance suggest that people with relevant CHD risk factors found them useful and easy to comprehend. Overall, the cholesterol management leaflet tended to score slightly lower which may reflect the different nature of this module. Being a mandatory module, management choices were restricted. In contrast, the modules for BP, physical activity and smoking all had extensive information about treatment choices. The leaflets tended to score lowest on the section related to information about CHD but highest on the section about treatment choices. This finding reflects the aim of the leaflets which was to focus on flexibility and choice rather than to provide didactic information.

There are various strengths and weaknesses of the progressive approach used in this study. We have documented a clinically practical method for developing and testing patient information materials that involved patients and health professionals throughout. However, only a small number of participants were involved for each phase and most did not have severe CHD. As only four key risk factors were chosen for development into modules and corresponding leaflets, future research could investigate modules and leaflets for all modifiable CHD risk factors. Also, as the leaflets were only compared to the existing information leaflet from one cardiac rehabilitation program, comparison of the leaflets with patient information from a diverse range of cardiac rehabilitation programs would be beneficial.

\section{Conclusion}

Using a three phase approach including qualitative and quantitative research methods, a series of risk factor modules and corresponding information leaflets have been developed and tested. Importantly, this study describes a readily applicable systematic process for designing and validating written patient information. This study also documents the unique perspective of persons with CHD risk factors. The leaflets are now considered suitable for use in further studies to test the effectiveness of a modular approach to secondary prevention of $\mathrm{CHD}$ and are expected to contribute to shared-decision making, patient empowerment and active patient participation.

\section{Competing interests}

The author(s) declare that they have no competing interests.

\section{Authors' contributions}

$\mathrm{JR}, \mathrm{EE}, \mathrm{TB}$ and BF were responsible for the design of the study. All authors read and approved the final manuscript.

\section{Acknowledgements}

The authors wish to thank the participating patients and staff at Concord Hospital in the Cardiology and Medical Records Departments. This work was supported by the National Heart Foundation of Australia in the form of a Grant-In-Aide and a Postgraduate Clinical Research Scholarship for Julie Redfern. We also thank The University of Sydney (one year scholarship for Julie Redfern) and the Cardiac Society of Australian and New Zealand (Travel Grant for Julie Redfern).

\section{References}

I. Miller WR, Rollnick S: Motivational Interviewing - Preparing people for change. 2nd edition. New York: The Guilford Press; 2002.

2. Rossouw JE, Lewis B, Rifkind BM: The value of lowering blood cholesterol after myocardial infarction. $N$ Engl J Med 1990, 323: I I I2-1 II9.

3. Gordon NF, Haskell WL: Comprehensive cardiovascular disease risk reduction in a cardiac rehabilitation setting. $\mathrm{Am} J$ Cardiol 1997, 80:69H-73H.

4. McAlister FA, Lawson FME, Teo KK, Armstrong PW: Randomised trials of secondary prevention programs in coronary heart disease: systematic review. Br Med J 200I, 323:957-962.

5. Aroney C, Boyden A, Jelinek M, Thompson P, Tonkin A, White H: Management of unstable angina, Guidelines - 2000. Med J Aust 2000, I 73:S65-S88.

6. WHO-ISH - The Guidelines Subcommittee of the WHO-ISH Mild Hypertension Liason Committee: Guidelines for the management of mild hypertension. Memorandum from the World Health Organisation - International Society of Hypertension Meeting. JHypertens 1993, I I:905-918.

7. Bunker $\mathrm{S}, \mathrm{McBurney} \mathrm{H}$, Cox $\mathrm{H}$, Jelinek M: Identifying participation rates at outpatient cardiac rehabilitation programs in Victoria, Australia. J Cardiopulm Rehab 1999, 19:334-8.

8. Scott IA, Lindsay KA, Harden HE: Utilisation of outpatient cardiac rehabilitation in Queensland. Med J Aust 2003, I 79:34|-345.

9. Bethell HJ, Turner SC, Evans JA, Rose L: Cardiac Rehabilitation in the United Kingdom. How complete is the provision? J Cardiopulm Rehab 2001, 2 I: I I I-I I5.

10. Harlan WR, Sandler SA, Lee KL, Lam LC, Mark DB: Importance of baseline functional and socioeconomic factors for participation in cardiac rehabilitation. Am J Cardiol 1995, 76:36-39.

II. Thomas RJ, Miller NH, Lamendola C, Berra K, Hedback B, Durstine $\mathrm{J}$, Haskell W: National survey on gender differences in cardiac rehabilitation programs: patient characteristics and enrollment patterns. J Cardiopulm Rehabil 1996, I6:402-12.

12. Briffa $T$ : Costs and benfits of existing and new cardiac rehabilitation strategies. In PhD Thesis Faculty of Medicine, University of Sydney; 2000.

13. Merz CNB, Rozanski A: Remodeling cardiac rehabilitation into secondary prevention programs. Am Heart J 1995, I 32:4 I 8-427.

14. Turnball A: How nurses can develop good patient information leaflets. Nurs Times 2003, 99:26-27.

15. Coulter A: Partnerships with patients: the pros and cons of shared clinical decision-making. J Health Serv Res Policy 1997, 2:||2-|2|.

16. Rollnick S, Allison J, Ballasiotes, Barth T, Butler CC, Rose GS, Rosengren DB: Variations on a theme: motivational interviewing and its adaptations (Chap I8). In Motivational Interviewing - Pre- 
paring people for change 2nd edition. Edited by: Miller WR, Rollnick S. New York: The Guilford Press; 2002.

17. Coulter A, Entwistle V, Gilbert D: Informing patients: An Assessment of the Quality of Patient Information Material. London: King's Fund; 1998.

18. Schulman BA: Active patient orientation and outcomes in hypertensive treatment. Med Care 1979, 17:267-280.

19. Simpson M, Buckman R, Stewart M, Maguire P, Lipkin M, Novack D, Till j: Doctor-patient communication: the Toronto consensus statement 1991.

20. Brody DS, Miller SM, Lerman CE, Smith DG, Caputo GC: Patient perception of involvement in medical care: relationship to illness attitudes and outcomes. J Gen Intern Med 1989, 4:506-5II

21. Stewart MA: Effective physician-patient communication and health outcomes: A review. CMAJ 1995, 152:1423-1433.

22. Roter DL: Patient participation in patient provider interaction: the effects of patient question-asking on the quality of interaction, satisfaction and compliance. Health Educ Monogr 1997, 5:28I-3I5.

23. Kaplan SH, Greenfield S, Ware JE: Assessing the effects of physician-patient interactions on the outcomes of chronic disease. Med Care 1989, 27:SIIO-SI27.

24. Etchells E: A safe, effective adjunctive treatment for arthritis, and pretty much every other condition you'll ever treat. Rheumatol 1999, 26:1647-1649.

25. Ley $\mathrm{P}$ : Satisfaction, compliance and communication. $\mathrm{Br} J \mathrm{Clin}$ Psychol 1982, 21:241-254.

26. Barlow JH, Pennington DC, Bishop P: Patient education leaflets for people with rheumatoid arthritis. Psychol Health Med 1997, 2:22I-235

27. Hill J, Bird HA, Harmer R, Lawton C, Wright V: An evaluation of the effectiveness, safety and acceptability of a nurse practitioner in a rheumatology outpatient clinic. Br J Rheumatol I994, 33:283-288.

28. Humphris GM, Duncalf M, Holt D, Field FA: The experimental evaluation of an oral cancer information leaflet. Oral Oncol 1999, 35:575-582

29. Michie S, Rosebert C, Heaversedge : The effects of different kinds of information on women attending an out-patient breast clinic. Psychol Health Med 1996, I:285-396.

30. Davison BJ, Kirk P, Degner LF, Hassard TH: Information and patient participation in screening for prostate cancer. Patient Educ Counsel 1999, 37:255-263.

31. Boyd M: A guide to writing effective patient education materials. Nurs Manage 1987, 18:56-57.

32. Centre for Health Information Quality: Quality issues in consumer health information. Reports from three quality forums held at the launch of the centre for health information Quality, Report Series I, Centre for Health Information Quality: Winchester 1997. Patient information leaflets for prostate cancer: which leaflets should healthcare professionals recommend? Patient Educ Couns 2003, 49:263-272.

33. Rienzo BA, Vitello EM: Development of patient education resource materials - A planned strategy. J Am Coll Health Assoc 1978, 27:224-225

34. Coulter A: Evidence based patient information: Is important, so there needs to be a national strategy to ensure it. $\mathrm{Br} M e d$ J 1998, 31 7:225-226.

35. Scotland A: Towards readability and style. Community Med 1985 , 7:126-132.

36. Hill J, Bird $\mathrm{H}$ : The development and evaluation of a drug information leaflet for patients with rheumatoid arthritis. Rheumatology 2003, 42:66-70.

37. Wilson F: The suitability of United States pharmacopoeia dispensary information psychotropic drug leaflets for urban patients with limited reading skills. Arch Psychiatr Nurs 1999, | 3:204-2 II.

38. Rees CE, Ford JE, Sheard CE: Patient information leaflets for prostate cancer: which leaflets should healthcare professionals recommend? Patient Educ Counsel 2003, 49:263-272.

39. Smith H, Gooding S, Brown R, Frew A: Evaluation of readability and accuracy of information leaflets in general practice for patients with asthma. Br Med J 1998, 317:264-265.

40. Smith PT, Cason CL: Suitability of patient education materials for cardiac catheterization. Clin Nurse Spec 1998, I 2: I40-I 44
4I. Bhopal RS, Gilmour WH, Fallon CW, Bhopal JS, Hamilton I: Evaluation of a practice information leaflet. Fam Pract 1990, 7:132-137.

42. Joshi HB, Newns N, Stainthorpe A, Macdonagh RP, Keeley FX, Timoney AG: The development and validation of a patientinformation booklet on ureteric stents. $\mathrm{Br} J$ Urol 200I, 88:329-334.

43. Zakrzewska JM, Leeson RM, McLuskey M, Vickers M: The development of patient information leaflets. Care of the mouth afterradiotherapy. Gerodontology 1997, I 4:48-53.

44. Charnock D, Shepperd S, Needham G, Gann R: DISCERN: an instrument for judging the quality of written consumer health information on treatment choices. J Epidemiol Community Health 1999, 53:105-III.

45. Godolphin W, Towle A, McKendry R: Evaluation of the quality of patient information to support informed shared decisionmaking. Health Expect 200I, 4:235-242.

46. Rees CE, Ford JE, Sheard CE: Evaluating the reliability of DISCERN: a tool for assessing the quality of written patient information on treatment choices. Patient Educ Counsel 2002, 47:273-275.

47. Flesch RR: A new readability yardstick. J Appl Psychol 1948 32:22I-223

48. Scott JT, Thompson DR: Assessing the information needs of post-myocardial infarction patients: a systematic review. Patient Educ Couns 2003, 50:167-177.

49. Meade CD, Smith CF: Readability formulas: Cautions and criteria. Patient Educ Counsel I99I, 17:153-I58.

50. Australian Institute of Health and Welfare (AIHW): Coronary Heart Disease. 200I [http://www.aihw.gov.au/cvd/majordiseases/ coronary.cfm].

51. Simes JC, Marschener IC, Hunt D, Colquhoun D, Sullivan D, Stewart RA, Hague W, Keech A, Thompson P, White H, Shaw J, Tonkin A, LIPID Study Investigators: Relationship between lipid levels and clinical outcomes in the Long-Term Intervention with pravastatin in ischaemic Disease (LIPID) Trial: To what extent is the reduction in coronary events with pravastatin explained by on-study lipid levels? Circulation 2002, 105: I 162-1 I69.

52. MacMahon S, Peto R, Cutler J, Collins R, Sorlie P, Neaton J, Abbott R, Godwin J, Dyer A, Stamler J: Blood pressure, stroke and coronary heart disease. Part I, prolonged differences in blood pressure: prospective observational studies connected for the regression dilution bias. Lancet 1990, 335:765-774.

53. Collins R, Peto R, MacMahon S, Hebert P, Fiebach NH, Eberlein KA, Godwin J, Qizilbash N, Taylor JO, Hennekens CH: Blood pressure, stroke and coronary heart disease. Part 2. Short-term reductions in blood pressure. Overview of randomised drug trials in their epidemiologic context. Lancet 1990, 335:827-838.

54. Australian Institute of Health and Welfare (AIHW): Heart, stroke and vascular diseases - Australian facts 2004. AlHW Cat. No. CVD 27. Canberra: AlHW; 2004

55. Hurley SF: Short-term impact of smoking cessation on myocardial infarction and stroke hospitalizations and costs in Australia. Med / Aust 2005, 183:13-17.

56. Blair SN, Kohl HW, Paffenbarger RS Jr, Clark DG, Cooper KH, Gibbons LW: Physical fitness and all-cause mortality: A prospective study of men and women. JAMA 1989, 262:2395-240I.

57. Doak CC, Doak LG, Root JH: Teaching patients with low literacy kills. 2nd edition. Philadelphia USA: Saunders; 1996.

\section{Pre-publication history}

The pre-publication history for this paper can be accessed here:

http://www.biomedcentral.com/1472-6963/6/95/prepub 